\title{
Glottik Tümörlerin Tedavisinde Vertikal ve Suprakrikoid Parsiyel Larenjektomi
}

\author{
Vertical and Supracricoid Laryngectomy for Treatment of Glottic Cancer
}

\author{
Ela CÖMERT ${ }^{1}$, Şahin ULU², Engin DURSUN ${ }^{3}, \mathrm{Necmi} \mathrm{ASLAN}^{4}$ \\ ${ }^{1}$ Ankara Onkoloji Eğitim ve Araştırma Hastanesi, KBB Kliniği, Ankara \\ ${ }^{2}$ Afyon Kocatepe Üniversitesi Tıp Fakültesi KBB AD, Afyonkarahisar \\ ${ }^{3}$ Recep Tayyib Erdoğan Üniversitesi Tıp Fakültesi KBB AD, Rize \\ ${ }^{4}$ Ankara Eğitim ve Araştırma Hastanesi KBB Kliniği, Ankara
}

\section{ÖZET}

Amaç: Çalışmamızda glottik kanser nedeniyle vertikal parsiyel larenjektomi (VPL) ve suprakrikoid parsiyel larenjektomi (SCPL) uygulanan hastalar retrospektif olarak incelenmiş ve bu iki cerrahi yöntemin onkolojik sonuçları araştrıımıştır.

Gereç ve Yöntem: Kulak Burun Boğaz kliniğinde 20012008 yılları arasında larenks kanseri tanısıyla primer olarak transservikal yöntemle VPL veya SCPL uygulanan 40 hasta incelemeye alındı.

Bulgular: Aspirasyon VPL yapılan hastaların \%10'unda, SCPL yapılan hastaların \%30'unda gözlendi. VPL ve SCPL'nin lokal kontrol oranları \%80 ve $\% 85$ olarak saptandı. Larenks korunma oranı VPL ile \%80, SCPL ile \%90 olarak saptandı. Üç ve 5 yıllık hastalıksız sağkalım oranları VPL ve SCPL için sırası ile $\% 79-\% 74$ ve $\% 85-\% 75$ olarak tesbit edildi.

Sonuç: Gerek SCPL gerekse VPL glottik tümörlerin tedavisinde kullanılan, düşük rekürrens ve yüksek larenks korunma oranlarına sahip, güvenilir cerrahi yöntemlerdir. VPL ile kıyaslandığında SCPL’nin komplikasyon oranı yüksektir.

Anahtar Kelimeler: Larinks kanseri; larenjektomi; sağkalım.

\section{ABSTRACT}

Objective: We retrospectively analyzed the patients who underwent vertical partial laryngectomy (VPL) and supracricoid laryngectomy (SCPL) for glottic cancer and the oncologic results of these surgical techniques.

Material and Methods: Forty patients who underwent VPL and SCPL for glottic cancer at Otolaryngology Clinic between 2001-2008 were included in the study.

Results: Aspiration occurred in $10 \%$ of the VPL patients and $30 \%$ of the SCPL patients. Local control rates of VPL and SCPL were $80 \%$ and 85 \%respectively. Larynx preservation rate was $80 \%$ for VPL and $90 \%$ for SCPL. Three and 5-year disease free survival rates of VPL and SCPL were $79 \%$ - 74 \%and 85 \%- 75 \%respectively.

Conclusion: Both VPL and SCPL are reliable surgical techniques that have low recurrence and high larynx preservation rates for the treatment of glottic cancer. When compared with VPL, SCPL has increased complication rates.

Keywords: Cancer of larynx; laryngectomy; survival.

\section{GíRiş}

Larenks kanseri \%25 oranla ikinci en sık görülen baş boyun malignitesidir (1). Larenks kanserlerinde tedavinin planlanmasında hastaya ait faktörler, tümörün evresi, larenks içi yayılımı, lenf nodu tutulumu, metastaz ve senkron sekonder primerin varlığı gibi faktörlerin detaylı incelenmesi gereklidir.
Yazışma Adresi / Correspondence: Op. Dr. Ela CÖMERT

Adres: Ankara Onkoloji Eğitim ve Araştırma Hastanesi 5. Kat KBB Kliniği 13. Cadde Demetevler 06200 Ankara

e-mail: drelacomert@gmail.com 
Erken evre (T1-T2) tümörlerin tedavisinde esas olarak endolarengeal lazer cerrahisi, açık parsiyel larenjektomi teknikleri ve Radyoterapi (RT) uygulanmaktadır. Ileri evre tümörlerin (T3-T4) ise tedavisinde kombine tedavi seçenekleri tercih edilmektedir. Bunlar kabaca parsiyel veya total larenjektomi, RT ve kemoradyoterapidir. Günümüzde RT ve kemoterapiyi içeren organ koruyucu protokoller total larenjektomiye alternatif olarak kullanılmaktadır.

Parsiyel larengeal cerrahinin amacı en azından bir fonksiyonel krikoaritenoid birimin korunması ile larenksin fonasyon ve respirasyon fonksiyonlarının devamını sağlamaya dayanır. Özellikle T2 glottik tümörlerin tedavisinde vertikal parsiyel larenjektomi (VPL) ve suprakrikoid parsiyel larenjektomi (SCPL) birçok vakada birbirinin alternatifi olarak kullanılabilecek yöntemlerdir (2-4).

Çalışmamızda glottik kanser nedeniyle VPL ve SCPL uygulanan hastalar retrospektif olarak incelenmiş ve bu iki cerrahi yöntemin onkolojik ve fonksiyonel sonuçları araştırılmıştır.

\section{GEREÇ ve YÖNTEM}

Kulak Burun Boğaz kliniğinde 2001-2008 yılları arasında larenks kanseri tanısıyla primer olarak transservikal yöntemle VPL veya SCPL uygulanan 40 hasta incelemeye alındı. Tanı anında veya öncesinde ek malignite saptanan veya kontrole gelmeyen vakalar çalışma dışı bırakıldı. Larenks kanseri ön tanısı ile incelenen her olguya anamnez, sistemik muayene ve kulak burun boğaz muayenesi yapıldı. Olgularda preoperatif endoskopik larenks muayenesi ve direk larengoskopi ile lezyon evrelendirilerek biyopsi ile histopatolojik tanı kondu.

Olguların preoperatif değerlendirilmesinde bilgisayarlı tomografi (BT), ultrason (USG) ve magnetik rezonans (MR) tetkiklerinden yararlanıldı. Tümörler 2002 TNM evreleme sistemine göre sınıflandırıldı.

Olguların yaşları, genel durumları, akciğer fonksiyonları, klinik evreleri, larenksteki kitlenin detaylı intraoperatif incelemeleri ve boyun metastazının varlığı veya olasılığı dikkate alınarak tedavi planlandı. Preoperatif değerlendirmede boyun metastazı şüphe veya tanısı bulunan veya okkült metastaz riski yüksek olan vakalara boyun diseksiyonu aynı seansta planlandı. Bilateral boyun diseksiyonu endikasyonu olan hastalara aynı seansta her iki boyun diseksiyonu beraber yapıldı.

Hastalara drenler çekilene kadar parenteral antibiyotik tedavisi rutin olarak verildi. Nazogastrik sonda tatbik edilen hastalar postoperatif 24 saat sonrası nazogastrik sondadan beslenmeye başlandı. Nazogastrik sonda tatbik edilmeyen hastalar ise yutma fonksiyonu yeterli olana kadar parenteral olarak beslendi. Postoperatif dönemde Göğüs Hastalıkları kliniği tarafindan aspirasyona bağlı akciğerde etkilenme düşünülen hastaların oranı, aspirasyon oranı olarak kabul edildi.

Postoperatif RT, cerrahi sınırda tümör olan, boyun diseksiyonu materyalinde metastaz tespit edilen olgularda, kemoterapi ise N2 ve üzeri evreli tümörlerde ve irrezektabl rekürrensli olgularda verildi.

Hastaların ilk bir yıl 1,5 ayda bir, ikinci yıl 3 aylık, sonrasında 6 aylık kontroller ile takipleri yapıldı. Çalışma Hastanemiz Eğitim Planlama Kurulu tarafindan onaylanmış olup Helsinki Deklerasyonu Prensipleri'ne uygun olarak düzenlenmiştir.

Hastaların 3 ve 5 yıllık hastalıksız sağkalım oranları Kaplan Meier yöntemi ile incelendi. Gruplar arası lokoregional kontrol ve sağkalım oranları arasındaki farklar log rank testi ile incelendi. Ki kare testi kullanılarak gruplar arasındaki orantısal farklar incelendi. Tüm veriler SPSS 15.0 programı kullanılarak incelendi. $p<0,05$ değerler anlamlı kabul edildi.

\section{BULGULAR}

Çalışmaya dahil edilen olguların hepsi erkek idi. Olguların yaşları 20 ile 71 arasında gözlendi. Cerrahi sonrası patoloji sonucu ile teyit edilen T evresine göre değerlendirildiğinde hastaların 5'i (\%12,5) T1, 29'u $(\% 72,5)$ T2, 6'sının (\%15) T3 olduğu gözlendi. Hastaların 37 'sine $(\% 92,5)$ lateral, fonksiyonel veya modifiye radikal boyun diseksiyonu yapıldı. $\mathrm{N}$ evresine göre değerlendirildiğinde hastaların 35'i $(\% 87,5)$ N0, 4'ü (\%10) N1, 1'i $(\% 2,5)$ N2 idi. Bir hastada ekstrakapsüler yayılım saptandı.

Alt hastada postoperatif patoloji sonucunda cerrahi sınırda tümör olduğu belirlendi. Bu hastalara 
postoperatif RT uygulandı. Toplam 7 (\%35) hastada rekürrens gözlendi. Rekürrens zamanı 9-28 ay arasında değişmekte idi. VPL yapılan vakaların 1'inde (\%5), SCPL yapılan hastaların 2'sinde (\%10) uzak metastaz (akciğer) saptandı.

Hastaların yaşı, T ve N evreleri, tümör diferansiasyonu, hastaların dekanülasyon zamanı ve aspirasyon oranları Tablo 1'de verilmiştir. Rekürrens ve sağkalıma ait bilgiler Tablo 2'de verilmiştir. Hastalıksız sağkalım oranları karşılaştirıldığında VPL ve SCPL uygulanan hastalar arasında 3 ve 5 yıllık sağkalım oranlarında istatistiksel fark saptanmadı. Beş yıllık hastalıksız sağkalıma ait Kaplan Meier grafiği Şekil 1'de verilmiştir. Larenks korunma oranı ve lokal kontrol oranı her iki grupta da benzer bulundu ( $p$ değerleri sırası ile 0,376 ve 0,677 ).
Postoperatif dönemde hastaların hepsinde yeterli solunum veya yutma fonksiyonu sağlanabildi.

\section{TARTIŞMA}

Artan bilgi ve cerrahi deneyimlerle fizyolojik konuşma ve trakeotomiye gerek olmadan nefes alabilmeyi sağlayacak ve aspirasyonu önleyecek yapının kord vokal değil krikoaritenoid ünite olduğu anlaşılmıştır. Bu nedenle tek krikoaritenoid ünite korunduğu sürece hasta larengeal koruma cerrahisi için adaydır (5).

Lezyonun üç boyutlu yayılımının değerlendirilmesi tedavi planı açısından büyük önem taşır. Erken evre invaziv glottik tümörlerde cerrahi seçenekler endoskopik mikrocerrahi veya lazer eksizyon, tirotomi

Tablo 1: Hastaların klinik özellikleri.

\begin{tabular}{|l|l|l|}
\hline Özellik & VPL grubu $(\mathrm{n}=20)$ & SCPL grubu $(\mathrm{n}=20)$ \\
\hline Yaş & $52(20-71)$ & $58(38-64)$ \\
\hline T evresi & & \\
\hline T1 & $5(\% 25)$ & - \\
\hline T2 & $15(\% 75)$ & $14(\% 70)$ \\
\hline T3 & - & $6(\% 30)$ \\
\hline N evresi & & \\
\hline N0 & $20(\% 100)$ & $15(\% 75)$ \\
\hline N1 & - & $4(\% 20)$ \\
\hline N2 & - & $1(\% 5)$ \\
\hline Ekstrakapsuler yayılım & - & $1(\% 5)$ \\
\hline Diferansiasyon & & \\
\hline İyi & $9(\% 45)$ & $7(\% 35)$ \\
\hline Orta & $9(\% 45)$ & $8(\% 40)$ \\
\hline Kötü & $2(\% 10)$ & $5(\% 25)$ \\
\hline Dekanülasyon zamanı, gün & $12(5-18)$ & $28(14-90)$ \\
\hline Aspirasyon & $2(\% 10)$ & $6(\% 30)$ \\
\hline
\end{tabular}

VPL: vertikal parsiyel larenjektomi, SCPL: Suprakrikoid parsiyel larenjektomi.

Tablo 2: Hastaların rekürrens ve sağkalım oranları.

\begin{tabular}{|l|l|l|l|}
\hline Özellik & VPL grubu ( $\mathrm{n}=20)$ & SCPL grubu $(\mathrm{n}=20)$ & $p$ değeri \\
\hline Lokal rekürrens & $4(\% 20)$ & $3(\% 15)$ & 0,677 \\
\hline Lokal rekürrens zamanı, ay & $18(12-28)$ & $11(9-22)$ & \\
\hline Lokal rekürrensin tedavisi & & & \\
\hline Total larenjektomi & $4(\% 20)$ & $2(\% 10)$ & \\
\hline Radyoterapi & - & $1(\% 5)$ & 0,677 \\
\hline Lokal kontrol oranı & $\% 80$ & $\% 85$ & 0,376 \\
\hline Larenks korunma oranı & $\% 80$ & $\% 90$ & 0,728 \\
\hline 3-yıllık hastalıksız yaşam oranı & $\% 79$ & $\% 85$ & 0,972 \\
\hline 5-yıllık hastalıksız yaşam oranı & $\% 74$ & $\% 75$ & \\
\hline
\end{tabular}

VPL: vertikal parsiyel larenjektomi, SCPL: Suprakrikoid parsiyel larenjektomi. 


\section{Survival Function}

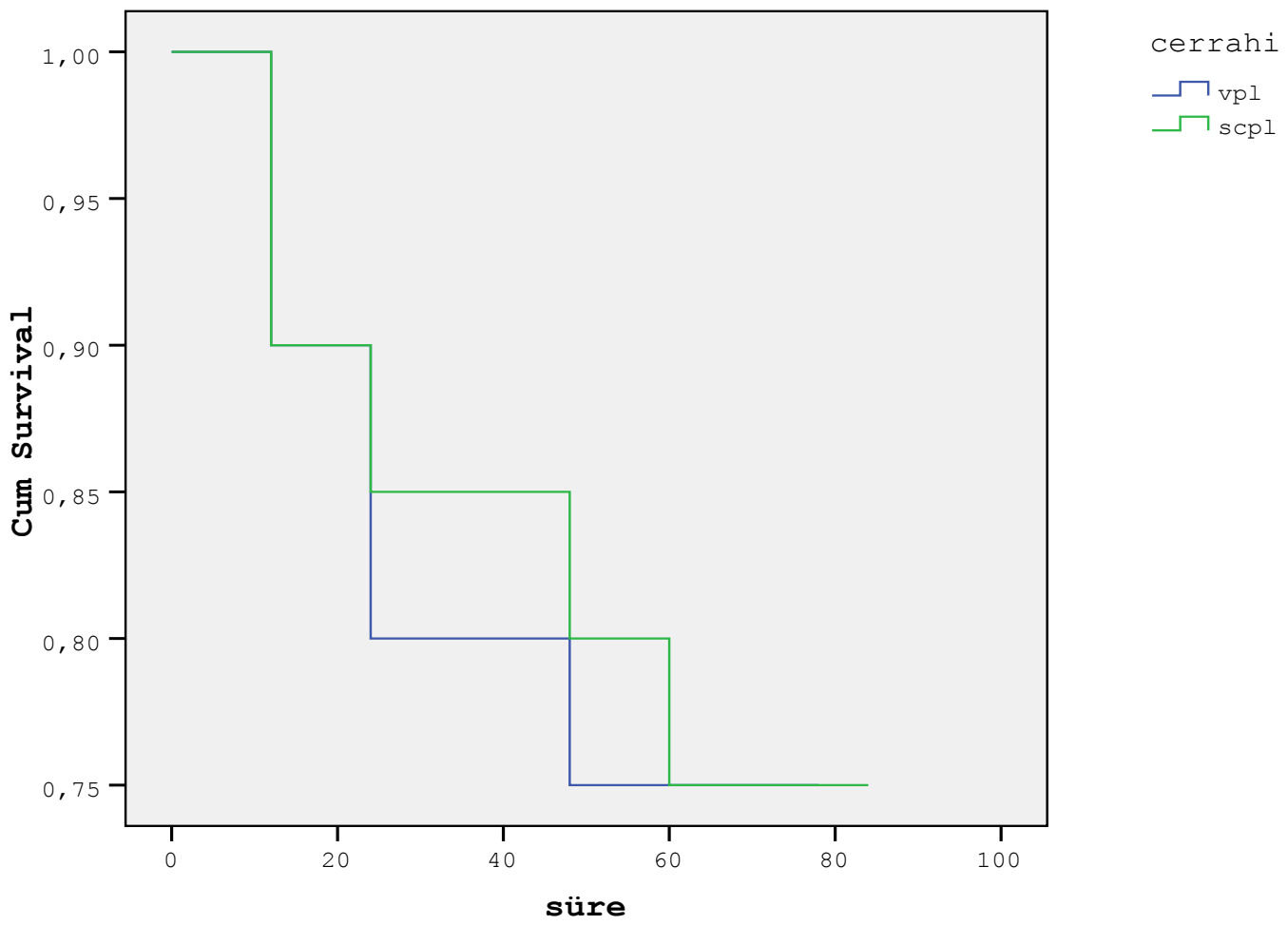

Şekil 1: 5 yılık hastalıksız sağkalımı gösteren Kaplan Meier grafiği.

ile kordektomi, vertikal parsiyel larenjektomiden radyoterapiye kadar uzanan geniş bir spektrumda incelenir (6). Yaptı̆̆ımız çalışmada $20 \mathrm{VPL}$ olgusundan 13'üne (\%65) frontolateral, 5 'ine (\%25) hemilarenjektomi, 2'sine (\%10) frontoanterior VPL uygulandı. Bu tedavi seçimini endikasyonlara uygun olarak tümörün supraglottik uzanımı, ön komissür ve karşı kord vokal ile olan ilişkisi yönlendirdi. Literatürde VPL uygulanan hastalarda lokal kontrol" oranı \%82,2 olup hastalıksız sağkalım \%77,8'dir (7). Çalışmamızda bu hastalardaki lokal kontrol oranı \%80 olup 3 ve 5 yıllık hastalıksız sağkalım oranları $\% 79$ ve $\% 74$ olarak saptandı.

Seçilmiş T2-3 supraglottik ve transglottik tümörlerde uygulanan, tek krikoaritenoid birimin korunmasını esas alan ve en geniş rezeksiyonun yapılmasına imkan tanıyan larengeal parsiyel cerrahi teknik SCPL'dir. Glottik ve supraglottik tutulumlu vakalarda özellikle ön komissür tutulumu mevcut ise lokal kontrol amacıyla
SCPL birçok yayında önerilmektedir (8-10). Ayrıca T1-2 ön komissür tutulumlu glottik tümörlü hastalarda RT ve VPL sonrası lokal rekürrens riski nedeniyle bu hastalara SCPL uygun bir tedavi seçeneğidir. Değişik yayınlarda lokal rekürrens oranları \%0-8 arasında değişmektedir $(11,12)$. SCPL sonrası lokal kontrol \%84- 95 olarak bildirilmiştir $(10,11,13)$. Üç yıllık sağkalım \%86,5 olarak rapor edilmiştir (11). Yaptı̆ı̆mız çalışmada SCPL'nin lokal kontrol oranı \%85 olup 3 ve 5 yıllık hastalıksız sağkalım oranı sırasıyla $\% 85$ ve $\% 75$ olarak saptandı.

Laccourreye ve ark. yaptıkları çalışmada T2 glottik vakalarda VPL ile SCPL'yi karşılaştırmış ve 10 yıllık lokal kontrol oranının, SCPL'de VPL'ye göre daha yüksek olduğunu tespit etmişlerdir (8). Lokal kontrol ve larenks korunma oranlarının VPL ile karşılaştırıldığında SCPL'de daha yüksek olduğu belirtilmiştir (7). Bunun nedenleri arasında VPL sırasındaki görüş kısıtlılığı ve SCPL sırasında tiroid kartilajın alınmasının sağladığı 
geniş cerrahi sınır yer alır (7). Fakat fonksiyonel olarak bakıldığında VPL yapılan hastalar geçici yutma zorlukları yaşarken SCPL yapılan hastalar uzun süreli ve şiddetli yutma zorluğu çekmektedir. SCPL uygulanan hastalarda aspirasyon daha sık olmakta ve dekanülasyon süresi uzamaktadır. Çalışmamızda iki cerrahi tekniğin de yüksek lokal kontrol oranı ve uzun dönem hastalıksız sağkalıma sahip olduğu gözlenmiştir. VPL yapılan hastaların \%60'ına nazogastrik sonda takılmamış olup postoperatif 2-3 gün parenteral beslenme sonrası oral beslenmeye geçilmiştir. SCPL yapılan hastaların ise hepsine nazogastrik sonda takılmış olup ortalama oral beslenmeye geçiş süresi 24 (18-52 gün) gündür. Aspirasyon VPL yapılan hastaların \%10'unda, SCPL yapılan hastaların \%30'unda gözlenmiştir. Cerrahi sırasında eksizyon yapılan dokuların artması ile beraber normal fizyolojinin bozulduğu, bu durumun komplikasyon artışının nedeni olduğu düşünüldü.

Gerek SCPL gerekse VPL glottik tümörlerin tedavisinde kullanılan güvenilir cerrahi yöntemlerdir. VPL, endolarengeal lazer cerrahisi ve RT tedavisindeki gelişmeler nedeniyle günümüzde giderek daha $a z$ tercih edilmektedir. SCPL ise ileri evre birçok tümörde total larenjektomiye alternatif olabilen ve larenks fonksiyonunu koruyan etkin bir cerrahidir.

\section{Teşekkür}

Yetişmemizde emeği olan, tez danışmanım değerli hocamız rahmetli Doç. Dr. Mehmet Turanlı'yı anmayı borç biliriz.

\section{KAYNAKLAR}

1. Kaya S (Editör). Larenks hastalıkları. 1inci Baskı, Ankara: Bilimsel Tıp Yayınevi, 2002:539-81.

2. Laccourreye $H$, Laccourreye $O$, Weinstein $G$, Menard M, Brasnu D. Supracricoid laryngectomy with cricohyoidoepiglottopexy: a partial laryngeal procedure for glottic carcinoma. Ann Otol Rhinol Laryngol 1990;99(6 Pt 1):421-6.

3. Brasnu DF. Supracricoid partial laryngectomy with cricohyoidopexy in the management of laryngeal carcinoma. World J Surg 2003;27(7):817-23.
4. Sanchez-Cuadrado I, Castro A, Bernaldez R, Del Palacio A, Gavilan J. Oncologic outcomes after supracricoid partial laryngectomy. Otolaryngol Head Neck Surg 2011;144(6):910-4.

5. Tufano RP. Organ preservation surgery for laryngeal cancer. Otolaryngol Clin N Am 2002;35(5):1067-80.

6. Myers EN, Suen JY, Myers JN, Hanna EN (Editörler). Cancer of the head and neck. In: Kacker A, Wolden S, Pfister DG, Kraus DH. Cancer of the larynx. 4th Edition, USA: Elsevier Science, 2003:333-79.

7. Zhang SY, Lu ZM, Chen LS, et al. Supracricoidpartial laryngectomy cricohyoidoepiglottopexy (SCPL-CHEP) versus vertical partial laryngectomy for the treatment of glottic carcinoma. Eur Arch Otorhinolaryngol 2013;270(3):1027-34.

8. Laccourreye O, Laccourreye L, Garcia D, et al. Vertical parsiel laryngectomy versus supracricoid parsiel laryngectomy for selected carcinomas of the true vocal cord classified as T2NO. Ann Otol Rhinol Laryngol 2000;109(10 Pt1):965-71.

9. Laccourreye $\mathrm{O}$, Muscatello L, Laccourreye L, et al. Supracricoid parsiel laryngectomy with cricohyoidoepiglottopexy for early glottic carcinoma classified as T1-T2N0 invading the anterior commissure. Am J Otolaryn 1997;18(6):385-90.

10. Bron L, Brossard E, Monnier P, Pasche P. Supracricoid parsiel laryngectomy with cricohyoidoepiglottopexy and cricohyoidopexy for glottic and supraglottic carcinomas. Laryngoscope 2000;110(4):627-34.

11. Laccourreye $H$, Laccourreye $O$, Weinstein $G$, Menard M, Brasnu D. Supracricoid laryngectomy with cricohyoidopexy: a partial laryngeal procedure for selected supraglottic and glottic carcinomas. Laryngoscope 1990;100(7):765-71.

12. Laccourreye $O$, Brasnu $D$, Biacabe B, et al. Neo-adjuvant chemotherapy and supracricoid partial laryngectomy with cricohyoidopexy for advanced endolaryngeal carcinoma classified as T3-T4: 5 year oncological results. Head Neck 1998;20(7):595-9.

13. Dufour X, Hans S, De Mones E, et al. Local control after supracricoid partial laryngectomy for "advanced" endolaryngeal squamous cell carcinoma classified as T3. Arch Otolaryngol Head Neck Surg 2004;130(9):1092-9. 
